\title{
Cavopulmonary assist: Long-term reversal of the Fontan paradox
}

\author{
Mark D. Rodefeld, MD, ${ }^{\mathrm{a}}$ Alison Marsden, $\mathrm{PhD},{ }^{\mathrm{b}}$ Richard Figliola, $\mathrm{PhD},{ }^{\mathrm{c}}$ Travis Jonas, BS, ${ }^{\mathrm{d}}$ \\ Michael Neary, MS, ${ }^{e}$ and Guruprasad A. Giridharan, $\mathrm{PhD}^{f}$
}

\section{ABSTRACT}

Objective: Fontan circulatory inefficiency can be addressed by replacing the missing subpulmonary power source to reverse the Fontan paradox. An implantable cavopulmonary assist device is described that will simultaneously reduce systemic venous pressure and increase pulmonary arterial pressure, improving preload and cardiac output, in a univentricular Fontan circulation on a longterm basis.

Methods: A rotary blood pump that was based on the von Karman viscous pump was designed for implantation into the total cavopulmonary connection (TCPC). It will impart modest pressure energy to augment Fontan flow without risk of obstruction. In the event of rotational failure, it is designed to default to a passive flow diverter. Pressure-flow performance was characterized in vitro in a Fontan mock circulatory loop with blood analog.

Results: The pump performed through the fully specified operating range, augmenting flow in all 4 directions of the TCPC. Pressure rise of 6 to $8 \mathrm{~mm} \mathrm{Hg}$ was readily achieved, ranging to $14 \mathrm{~mm} \mathrm{Hg}$ at highest speed (5600 rpm). Performance was consistent across a wide range of cardiac outputs. In stalled condition $(0 \mathrm{rpm})$, there was no discernible pressure loss across the TCPC.

Conclusions: A blood pump technology is described that can reverse the Fontan paradox and may permit a surgical strategy of long-term biventricular maintenance of a univentricular Fontan circulation. The technology is intended for Fontan failure in which right-sided circulatory inefficiencies predominate and ventricular systolic function is preserved. It may also apply before clinical Fontan failure as health maintenance to preempt the progression of Fontan disease. (J Thorac Cardiovasc Surg 2019;158:1627-36)

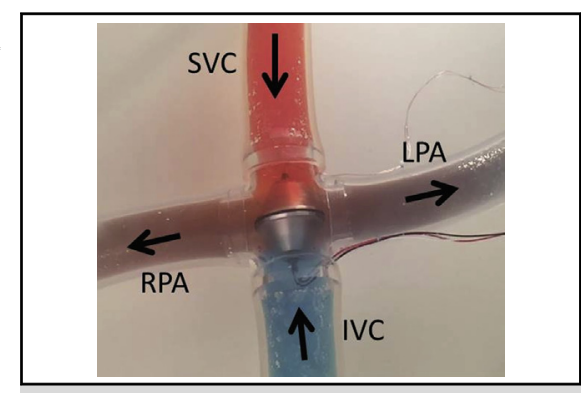

Cavopulmonary assist device: flow augmentation through the total cavopulmonary connection.

\section{Central Message}

An implantable blood pump that can safely and reliably reverse the Fontan paradox for the long term may enable a physiologically curative strategy for single-ventricle heart disease.

\section{Perspective}

Fontan palliation is associated with a chronic circulatory inefficiency that culminates in secondary disease, failure, and attrition. We report the feasibility of an implantable cavopulmonary assist device that can safely replace the missing subpulmonary power source and reverse the Fontan paradox for the long term. This may enable a physiologically curative strategy for single functional ventricle.

See Commentaries on pages 1637 1639 , and 1641.
Repair of single functional ventricle currently consists of a staged surgical approach that terminates in a univentricular Fontan circulation. Since its introduction, Fontan palliation has dramatically improved the outcome for all forms of single-ventricle heart disease ${ }^{1,2}$; however, survivors of the Fontan procedure are committed for the remainder of

From the ${ }^{\text {a Section }}$ of Cardiothoracic Surgery, Department of Surgery, Indiana University School of Medicine and James Whitcomb Riley Hospital for Children, Indianapolis, Ind; ${ }^{\mathrm{b}}$ Department of Bioengineering and Pediatrics, Stanford University, Stanford, Calif; ' Department of Mechanical Engineering, Clemson University, Clemson, SC; ${ }^{\mathrm{d}}$ Mechanical Solutions Inc, Whippany, NJ; ${ }^{\mathrm{e}}$ Rotor Bearing Technology and Software Inc, Phoenixville, Pa; and ${ }^{\mathrm{f}}$ Department of Bioengineering, University of Louisville, Louisville, Ky.

Supported in part by National Institutes of Health Bioengineering Research Grant R01 HL098353, Big Hearts to Little Hearts, Children's Heart Foundation, Matthews Hearts of Hope. their lives to a state of chronic circulatory inefficiency because of the lack of a subpulmonary ventricle. This inefficiency results in coexisting elevated systemic venous pressure and reduced cardiac output, known clinically as the Fontan paradox. ${ }^{3}$ Combined, these problems have been clearly shown to progress to late Fontan failure and
Read at the 99th Annual Meeting of The American Association for Thoracic Surgery, Toronto, Ontario, Canada, May 4-7, 2019.

Received for publication May 2, 2019; revisions received June 13, 2019; accepted for publication June 14, 2019; available ahead of print Sept 26, 2019.

Address for reprints: Mark D. Rodefeld, MD, Section of Cardiothoracic Surgery, Indiana University School of Medicine, Emerson Hall 215, 545 Barnhill Dr, Indianapolis, IN 46202 (E-mail: rodefeld@iupui.edu). $0022-5223 / \$ 36.00$

Copyright (c) 2019 by The American Association for Thoracic Surgery https://doi.org/10.1016/j.jtcvs.2019.06.112 


\section{Abbreviations and Acronyms \\ MCS = mechanical circulatory support \\ $\mathrm{TCPC}=$ total cavopulmonary connection}

Scanning this QR code will take you to the article title page to access supplementary information.

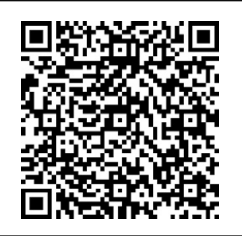

attrition. ${ }^{4}$ Despite extensive clinical and research efforts, therapies to prevent or reverse this circulatory decline remain extremely limited, with no breakthroughs for decades. ${ }^{5}$ With an increasing number of late survivors of the Fontan operation, Fontan failure is now a routinely encountered and challenging clinical problem.

We have theorized that replacement of the missing subpulmonary power source would reverse the Fontan paradox and shift the univentricular circulation toward more stable biventricular equivalency. ${ }^{6}$ It would decongest the systemic venous and lymphatic circulations, while simultaneously improving cardiac output. If applied as durable long-term support, it could in theory preempt Fontan-associated disease progression by maintaining biventricular equivalency.

Despite the simplicity and attractiveness of this concept, the technologic considerations are complex and dissimilar to any other mechanical circulatory support (MCS) application. We have found that existing MCS technologies are ill-suited and unmodifiable to address Fontan circulatory inefficiency. Alternatively, we have focused on the development of an anatomically specific device that can replace the missing subpulmonary power source and reverse the Fontan paradox. ${ }^{7}$ This report describes the computational and in vitro basis for an implantable cavopulmonary assist device concept that has potential to restore biventricular equivalency safely and durably in a univentricular circulation.

\section{METHODS \\ Pump Design}

In previous studies, we have demonstrated that a remotely powered rotary pump, which was based on the von Karman viscous pump, can provide 4-way flow augmentation through the total cavopulmonary connection (TCPC). ${ }^{7}$ A biconical impeller suspended in the midst of the TCPC functions as a 2-sided centrifugal pump, drawing inflow from the superior and inferior venae cavae and augmenting outflow to the left and right pulmonary arteries at physiologic pressure. A modest pressure step-up of $6 \mathrm{~mm} \mathrm{Hg}$ has been shown in vitro and in vivo to restore the univentricular Fontan circulation to biventricular equivalency under normal physiologic conditions. ${ }^{6,7}$ We have also demonstrated that a cavopulmonary assist device that is based on the von Karman viscous pump will not obstruct the systemic venous pathway in the event of rotational dysfunction and will instead reduce kinetic energy loss in the TCPC. ${ }^{7}$

Because an external power source would limit such a device to temporary use, a permanent power source was incorporated in the form of an outrunner brushless direct current motor. In an outrunner motor, the rotating component is outside rather than inside (Figure 1). For an in-series pump situated in the Fontan venous pathway, this configuration is key to eliminating the risk of venous pathway obstruction because it allows preservation of a wide passage between the impeller and housing. As a result, the pump can serve in 2 distinctly different capacities: rotating, it functions as a pump; non-rotating, it functions as a static flow diverter (Figure 2). Thus, it is intended to be beneficial even if it fails.

A biconical stator, containing iron laminations and copper windings, is located centrally within the impeller, and has no blood contact or moving parts. It is surrounded by a biconical rotor with embedded magnets as the only moving component. Rotor surface vanes provide low-pressure, high-volume augmentation of cavopulmonary flow (Video 1). A secondary (internal) flow path between the rotor and the stator is an inherent centrifugal pump and integrates several key functions: (1) electromagnetic flux transfer for motor torque, (2) heat dissipation, (3) bearing lubrication, and (4) rotodynamic stabilization (Video 2). The housing is a double-inlet, double-outlet, thin-walled, hard case shell that serves only to direct TCPC flow and structurally suspend the pump. Wiring from the stator travels through the central shaft to exit the housing via shaft struts. Because there is no external component bulk, the pump is no larger than the native TCPC and is suitable for in situ implantation.

\section{Pump Fabrication and Testing}

An advanced prototype was designed and fabricated at adult scale (25 mm diameter inlets, $20 \mathrm{~mm}$ diameter outlets; Figure 3). With the aid of computational fluid dynamic modeling, impeller dimension and motor size were determined on the basis of the torque required to achieve a pressure rise of 6 to $8 \mathrm{~mm} \mathrm{Hg}$ under physiologic conditions. Noncircumferential conical bearings support the rotor at each end. The impeller surface vane height is only $0.7 \mathrm{~mm}$. The pump was tested initially in an open circuit, with no baseline imposed flow, with blood analog (water/glycerin 63:37, physiologic density $1060 \mathrm{~kg} / \mathrm{m}^{3}, 3.2 \mathrm{cP}$ ). Testing was then performed in a static loop for pressure-flow performance and finally in vitro in a mock loop of a Fontan circulation for physiologic performance. For static performance, the pump was operated at 0 to $5600 \mathrm{rpm}$ against 5 different resistances. Steady-state pressure head and flow rates
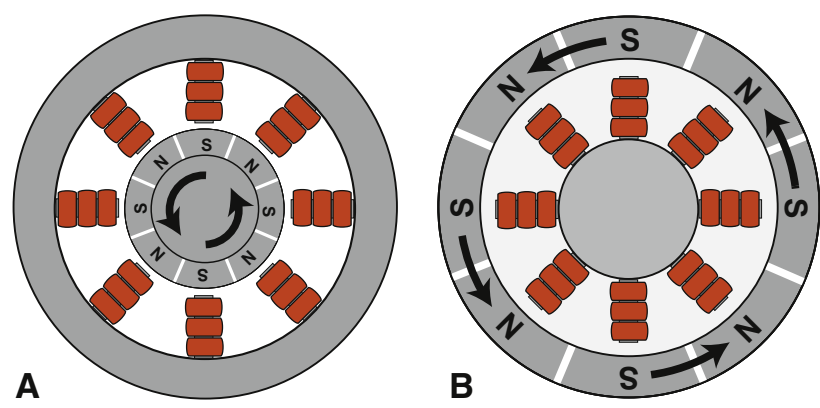

FIGURE 1. Outrunner brushless direct current motor. A, Traditional motor design with inner rotating component fabricated with permanent magnets driven by the outer, stationary motor windings, depicted in orange. $\mathrm{B}$, Outrunner motor design with outer rotating component with permanent magnets driven by stationary central motor windings, depicted in orange. The outer rotating component is a critical innovation that enables the cavopulmonary assist device to be implanted within the total cavopulmonary connection. 

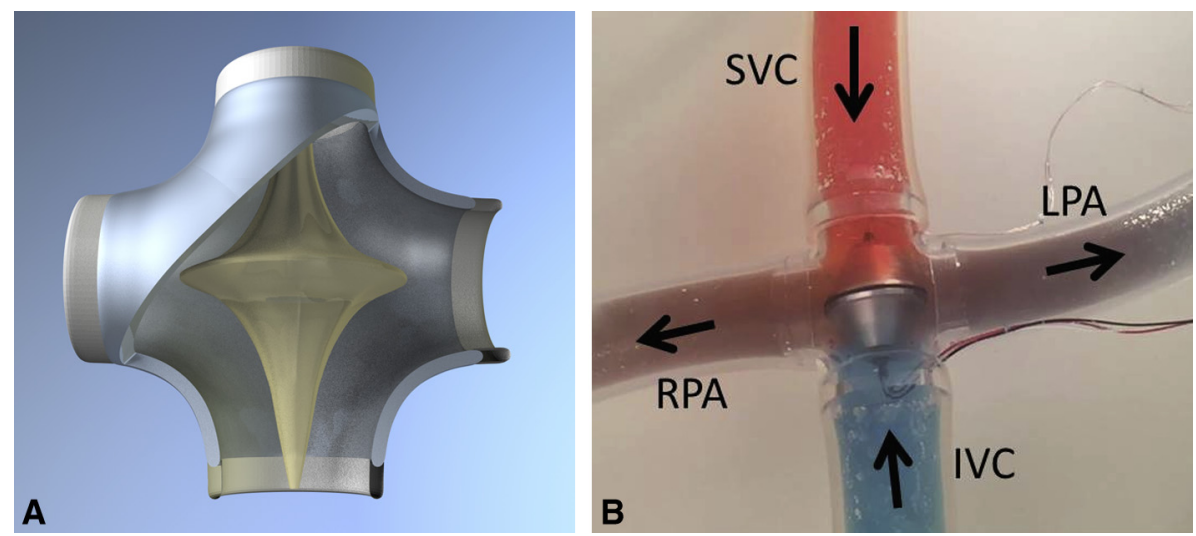

FIGURE 2. Implantable cavopulmonary assist device. A, Conceptual image. A central impeller contains the motor (impeller support shaft and struts not shown). The external housing is a thin-walled, hard case shell that has no component bulk and serves only to direct Fontan flow. The wide gap between the impeller and the housing must support passive total cavopulmonary connection flow at low resistance in the event of device dysfunction. B, Advanced prototype image depicting pump function. Color contrast demonstrates superior vena caval (SVC) flow (red) and inferior vena caval (IVC) flow (blue) mixing to both left pulmonary arterial (LPA) and right pulmonary arterial (RPA) outlets (purple).

were plotted to characterize hydraulic (pressure-flow) performance. Inlet partial and complete occlusion performances were assessed. For physiologic performance testing, a Fontan mock circulatory system was used that includes compliance and resistance elements. ${ }^{7}$

\section{RESULTS}

All design objectives were met, including the following: (1) pressure-flow performance of 0 to $14 \mathrm{~mm} \mathrm{Hg}$ pressure rise at 0 to $5600 \mathrm{rpm}$; (2) mean scalar shear stress less than $100 \mathrm{~Pa}$, transit time less than 0.01 seconds; (3) noncavitating performance; (4) acceptable recirculation; and (5) no pressure loss in the static condition $(0 \mathrm{rpm})$. Heat dissipation was excellent, confirmed by reduction of core temperature at higher speed and no measurable increase in blood analog temperature $\left(<0.1^{\circ} \mathrm{C}\right)$. Hydraulic performance was consistent across a wide range of cardiac output

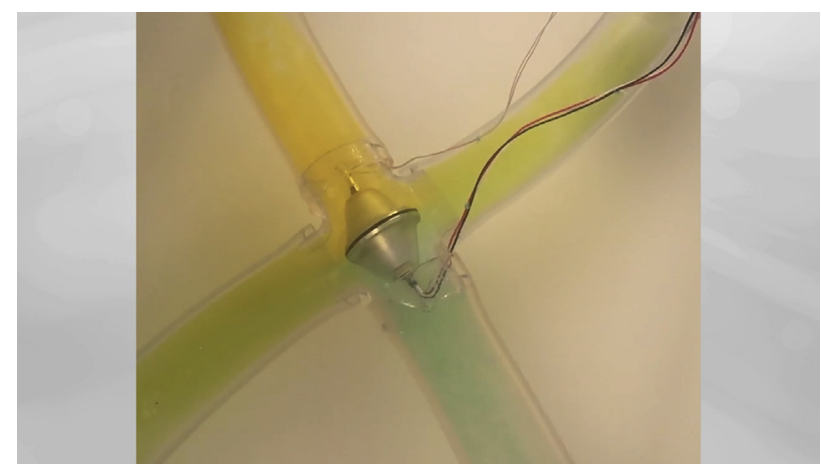

VIDEO 1. Primary (external) flow path. With an open static circuit, flow is induced by the pump. Yellow and blue contrast represent systemic venous inflow. The green outflow represents left and right pulmonary arterial flow. Mixing indicates symmetric hepatic factor distribution. Video available at: https://www.jtcvs.org/article/S0022-5223(19)31676-9/fulltext.
(Figure 4). A peak pressure of $14 \mathrm{~mm} \mathrm{Hg}$ was achieved at the highest speed. The pump generated $5 \mathrm{~L} / \mathrm{min}$ of flow and $6 \mathrm{~mm} \mathrm{Hg}$ pressure head at $4000 \mathrm{rpm}$, and $5 \mathrm{~L} / \mathrm{min}$ of flow and $8 \mathrm{~mm} \mathrm{Hg}$ pressure head at $5600 \mathrm{rpm}$. The in vitro pump performance was consistent with the design specifications and computational fluid dynamic modeling (6-8 $\mathrm{mm} \mathrm{Hg}$ pressure rise under physiologic conditions). The pump generated inflow from both the superior and inferior venae cavae equally to both pulmonary arteries for superior to inferior vena caval inflow ratios ranging from 30:70 to 50:50. The pump effectively mixed inflows from both inlets, with consistently symmetric outflow distribution (of importance to hepatic factor distribution; Video 1). The power draw was less than $6 \mathrm{~W}$ at maximal speed,

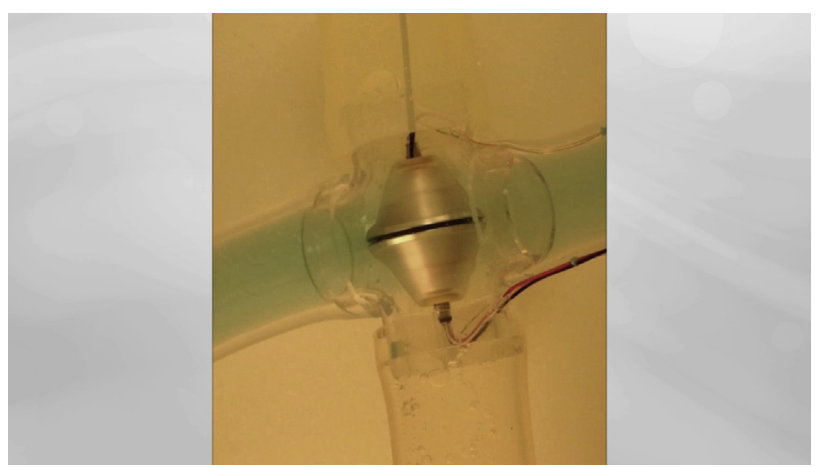

VIDEO 2. Secondary (internal) flow path. With an open static circuit, flow is induced by the pump. Contrast injection flows selectively through the internal flow path, with dispersion of outflow at the equatorial midline. Internal path flow is essential to pump function for heat dissipation, for bearing flushing, and to reduce risk of recirculation, stasis, and thrombosis. Video available at: https://www.jtcvs.org/article/S0022-5223(19)31676-9/ fulltext. 

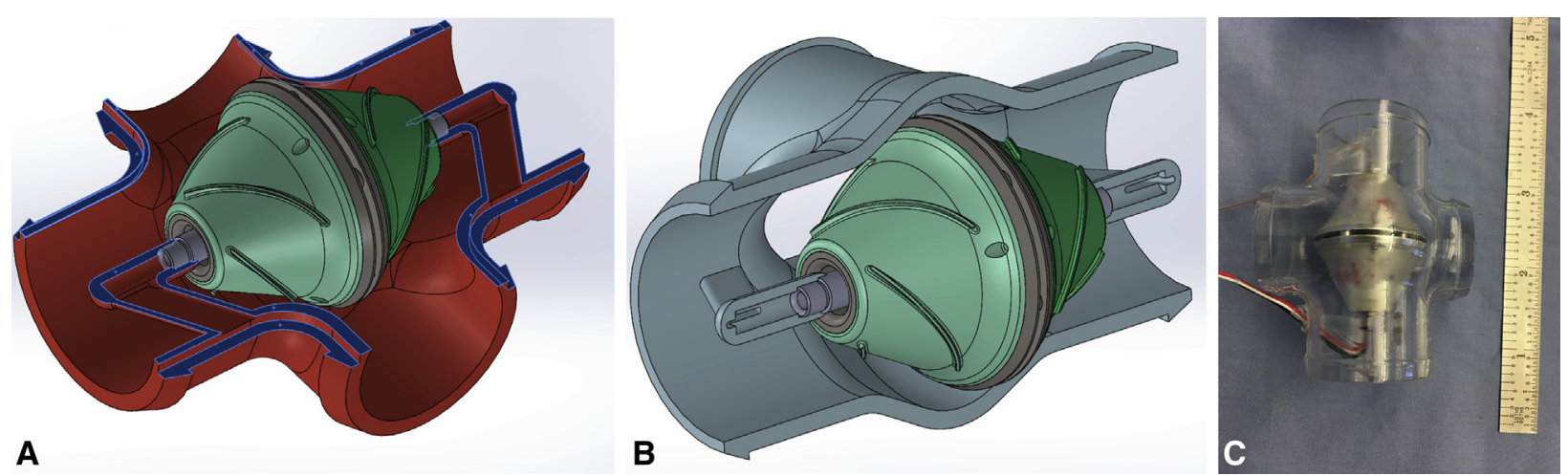

FIGURE 3. Advanced prototype, adult scale. A, Design solid model showing housing, support struts, and motor, with mounted impeller. Wiring travels from the stator through the central shaft and strut to exit the housing. A thermocouple embedded in the stator core was used to monitor device operating temperature. The intrinsic heat-sink properties of the internal flow path result in excellent heat performance, as observed by a decrease in core temperature at higher speeds. The only moving component is the rotor. A secondary flow path allows for inflow at each axial end, with outflow at the equatorial gap (Video 2). B, Design schematic showing patulous channel to prevent obstruction in the event of rotational failure. Rotor surface shows $0.7 \mathrm{~mm}$ height curved surface vanes. C, Assembled prototype as tested and demonstrated in the videos.

and this is expected to improve with further optimization. Because the surface vane profile is so low, there is flexibility to increase vane height for higher pressure performance without compromising the no-obstruction constraint.

In in vitro physiologic mock loop testing, the device effectively reversed the Fontan (Table 1). With increasing rpm, ventricular end-diastolic pressure and aortic pressure increased. At $5000 \mathrm{rpm}$, the pump converted a cavopulmonary pressure head of positive $2.8 \mathrm{~mm} \mathrm{Hg}$ to negative $4.8 \mathrm{~mm} \mathrm{Hg}$, replacing a small energy loss with a

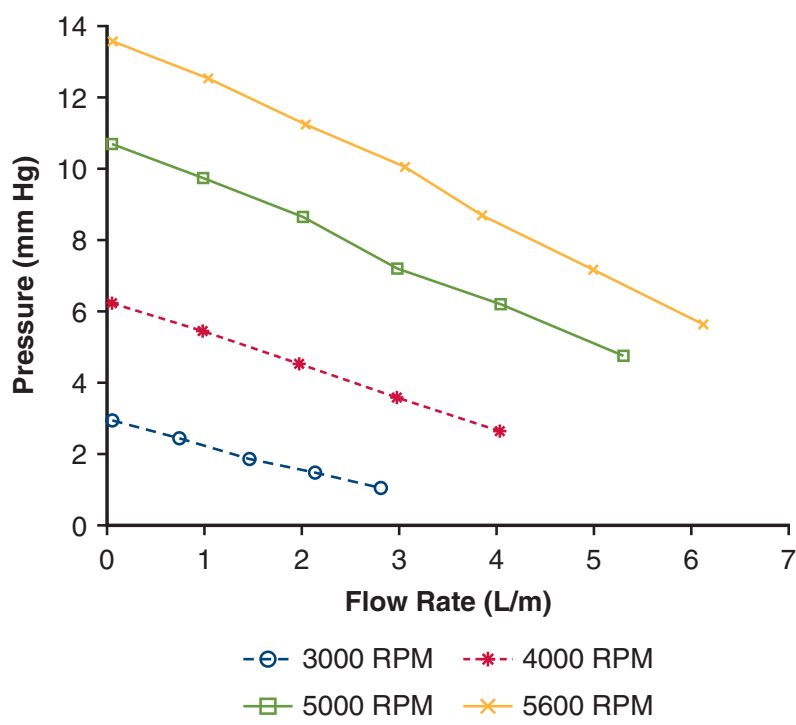

FIGURE 4. Hydraulic performance was tested in a static mock flow loop with 2 inlets, 2 outlets, a storage chamber, and variable outflow resistance. The pressure head generated was plotted against pump-generated flow for multiple levels of outflow resistance for various pump speed settings. The pressure-flow curve demonstrates that the cavopulmonary assist device is capable of producing as much as $14 \mathrm{~mm} \mathrm{Hg}$ pressure head. proportionally larger gain. It boosted pulmonary arterial pressure by $6 \mathrm{~mm} \mathrm{Hg}$ and increased preload sufficient to increase cardiac output by $12.8 \%$. Vena caval pressure was reduced $1.4 \mathrm{~mm} \mathrm{Hg}$, which is significant in this segment of the circulation, where even small reduction of pressure is beneficial to splanchnic health. Increase in pump speed beyond $5000 \mathrm{rpm}$ caused a larger negative cavopulmonary pressure head but did not lead to a measurable increase cardiac output. When the pump was stopped ( $0 \mathrm{rpm})$, there was no discernible pressure drop, validating the no-obstruction design constraint. Importantly, in the stopped condition, TCPC turbulence was reduced relative to the condition with no pump installed.

\section{DISCUSSION}

Among the many significant advances in the treatment of congenital heart disease during the past 5 decades, single-ventricle palliation has had perhaps the largest effect. Nonetheless, it was predicted by its innovators that it may be incompatible with a normal lifespan and require improvement or modification. ${ }^{8-10}$ As predicted, Fontan-associated disease now represents one of the most significant challenges in the field. Although Fontan palliation is lifesaving, it carries a lifelong chronic disease burden that has no primary preventive therapy and is ultimately life limiting. ${ }^{11,12}$ As a reflection of its palliative nature, late Fontan attrition is relatively constant, suggesting that immutable factors play a role, and 30-year survival is only $43 \%$ to $70 \%{ }^{13-15}$

Solutions to address Fontan-associated disease have been largely incremental and of unclear benefit, and we may have reached a plateau. Fontan optimization can at best only prolong an inherently inefficient system, because it does not address the underlying physiologic deficit: the lack of a subpulmonary ventricle. To date, little effort has focused on 
TABLE 1. In vitro mock loop testing demonstrating reversal of the failing Fontan circulation with cavopulmonary assist

\begin{tabular}{|c|c|c|c|c|c|c|c|c|}
\hline Case & $\begin{array}{c}\text { VIP speed } \\
(\text { rpm })\end{array}$ & $\begin{array}{c}\text { HR } \\
\text { (beats/min) }\end{array}$ & $\begin{array}{c}\text { CO } \\
(\mathrm{L} / \mathrm{min})\end{array}$ & $\begin{array}{c}\text { CO \% } \\
\text { increase }\end{array}$ & $\begin{array}{c}\text { VCP } \\
(\mathrm{mm} \mathrm{Hg})\end{array}$ & $\begin{array}{c}\text { PAP } \\
(\mathrm{mm} \mathrm{Hg})\end{array}$ & $\begin{array}{c}\text { CPPH } \\
(\mathrm{mm} \mathrm{Hg})\end{array}$ & $\begin{array}{c}\text { AoP } \\
(\mathrm{mm} \mathrm{Hg})\end{array}$ \\
\hline Fontan baseline & 0 & 75 & 3.9 & - & 17.5 & 14.7 & 2.8 & $98.3 / 57.4$ \\
\hline Fontan + VIP & 3000 & 75 & 4.1 & $5.1 \%$ & 17 & 16.6 & 0.4 & $102.3 / 60.5$ \\
\hline Fontan + VIP & 4000 & 75 & 4.3 & $10.3 \%$ & 16.8 & 18 & -1.2 & $111.9 / 66.7$ \\
\hline Fontan + VIP & 5000 & 75 & 4.4 & $12.8 \%$ & 16.1 & 20.8 & -4.8 & $113.6 / 69.0$ \\
\hline
\end{tabular}

At $5000 \mathrm{rpm}$, the pump converted a cavopulmonary pressure head of positive $2.8 \mathrm{~mm} \mathrm{Hg}$ to negative $4.8 \mathrm{~mm} \mathrm{Hg}$, replacing a small energy loss with a proportionally larger gain. It boosted pulmonary arterial pressure by $6 \mathrm{~mm} \mathrm{Hg}$ and increased preload sufficient to increase cardiac output by $12.8 \%$, demonstrating reversal of a failing Fontan circulation. Computational modeling and in vitro mock loop studies demonstrate consistent and symmetric outflow to the right and left pulmonary arteries. In clinical use, outflow distribution is expected to be affected by patient-specific pulmonary resistance. Fontan baseline includes pump in total cavopulmonary connection in stalled ( 0 rpm) condition. VIP, Viscous impeller pump; $H R$, heart rate; $C O$, cardiac output; $C O \%$ increase, percentage increase from baseline Fontan cardiac output; $V C P$, vena caval pressure; $P A P$, pulmonary artery pressure; $C P P H$, cavopulmonary pressure head (pump $\triangle \mathrm{P}=$ vena caval pressure - pulmonary artery pressure); $A o P$, aortic pressure.

mechanical replacement of a subpulmonary power source, presumably because a comprehensive solution is both not obvious and highly complex. Replacement of the missing subpulmonary power source is, however, physiologically compelling; it will normalize systemic venous pressure, decongest the lymphatic circulation, and normalize ventricular loading conditions, emulating biventricular efficiency. Given the ongoing problems with Fontan-associated disease, it is reasonable to reconsider the current paradigm. Rather than Fontan perpetuation, a preferable strategy may be to reverse the Fontan. ${ }^{16}$

\section{Fontan Failure Is Largely Nonventricular Failure}

Although patients with failing Fontan circulations may exhibit classic features of congestive heart failure, the primary cause is not typically ventricular systolic dysfunction. Before end-stage Fontan disease, ejection fraction is preserved in more than $70 \%$ of patients; diastolic dysfunction predominates. ${ }^{17}$ Although the mechanisms are complex and multifactorial, Fontan diastolic dysfunction has been largely attributed to chronic preload deprivation. $^{18,19}$ With time, abnormal loading conditions (decreased preload, increased afterload) result in cardiomyopathic remodeling and fibrosis, ${ }^{20}$ with eventual systolic dysfunction. It thus can be said that the Fontan circulation predisposes the single ventricle to fail. Furthermore, efforts that target improvement in ventricular function as a solution to Fontan disease may be misguided; it may be of greater benefit to provide cavopulmonary assistance.

Cavopulmonary assist specifically addresses the lack of a subpulmonary power source, and it will in turn normalize ventricular loading conditions and improve function. In the setting of diastolic dysfunction but preserved systolic function, a modest increase in preload (approximately 1-3 $\mathrm{mm} \mathrm{Hg}$ ) will improve myocardial performance and cardiac output (opposite primary myocardial failure).

Transplantation is, in a sense, a definitive therapy for Fontan failure, in that it reinstates a subpulmonary ventricle, but it does so at the cost of a different disease process. There are not sufficient donor organs available to provide transplants for all patients with single ventricle disease. Because of listing criteria, most patients with Fontan circulations will not receive a donor organ until they have end-stage disease with advanced comorbidities. Transplant survival of less than $50 \%$ at 10 years is arguably no better than the natural history of late Fontan attrition. ${ }^{21}$ For these reasons, transplantation is not a comprehensive solution and represents end-stage therapy.

\section{Fontan Optimization Falls Short}

Strategies to optimize Fontan hemodynamics have logically targeted the TCPC, where anatomic factors may result in significant power loss. ${ }^{22-24}$ These have included various vena caval offset configurations, as well as a Fontan $\mathrm{Y}$ conduit to reduce power loss in the inferior vena caval distribution. ${ }^{25}$ Although these modifications have been applied clinically, they have not had significant effect. The maximal pressure gain that can be derived from passive flow optimization (approximately 1-2 mm $\mathrm{Hg}$ ) does not fully correct the circulatory deficit and, as a result, does not meaningfully improve circulatory status. By comparison, consider normal biventricular physiology, in which the right ventricle provides a cavopulmonary pressure step-up of approximately 6 to $8 \mathrm{~mm} \mathrm{Hg}$. To make a clinically meaningful improvement in Fontan, it is necessary to add pressure energy at the TCPC by a similar amount.

\section{Limitations of Current MCS Technology Applied to Fontan Failure}

The application of existing MCS devices for Fontan failure is limited, highly variable, and associated with poor outcomes. $^{26-29}$ It has generally focused on the application of systemic support in end-stage Fontan disease because of the nature of existing technologies. Nearly all MCS technologies are intended for systemic support. Depending on the circumstances, however, the device is 
TABLE 2. Desirable technical features for a long-term cavopulmonary assist device

1. Simplicity: single pump, with 1 moving part, that serves as a low-input primer for the systemic ventricle.

2. Multidirectional flow: flow augmentation in all 4 distributions of the TCPC (SVC/IVC inflow, RPA/LPA outflow).

3. Low-pressure performance: low-pressure (approximately 6-8 $\mathrm{mm} \mathrm{Hg}$ ), high-volume flow augmentation, similar to normal right ventricular hemodynamics.

4. Wide performance range: consistent pressure rise across a wide range of cardiac outputs and variable physiologic demands, independent of pump speed.

5. Nonobstructive: an inline pump in the Fontan venous pathway must account for pump failure, with no obstruction risk as a failure default.

6. TCPC as the preferred default flow path: the failed $(0 \mathrm{rpm})$ condition should ideally optimize passive TCPC flow as an unsupported Fontan circulation.

7. Permissive preload and afterload performance: low hydraulic efficiency to reduce risks of both excessive negative upstream pressure (suction, vein collapse, cavitation) and excessive positive downstream pressure (perfusion lung injury). It will permit tolerance to the inflow instabilities of systemic venous return (supine vs upright posture, Valsalva).

8. Mixing: symmetric hepatic factor distribution to prevent pulmonary arteriovenous malformation (Video 1).

9. No barrier to recirculation: to reduce thrombogenicity and obstruction risk.

10. Small size: in situ implantation to avoid physical encroachment on adjacent structures (eg, aorta, common atrium, pulmonary veins).

$T C P C$, Total cavopulmonary connection; $S V C$, superior vena cava; $I V C$, inferior vena cava; $R P A$, right pulmonary artery; $L P A$, left pulmonary artery

likely mismatched to Fontan circulatory needs, that is, leftsided support to address a right-sided deficit. Anecdotally, existing MCS appears to be better suited for ventricular "pump" failure in Fontan circulations, rather than for Fontan failure secondary to lack of a subpulmonary ventricle. In the setting of preserved systolic function, systemic MCS in a Fontan circulation is redundant; it may needlessly congest the right-sided circulation where the circulatory bottleneck exists and exacerbate Fontan disease.

Existing MCS applied strategically to the right side of the Fontan circulation has been reported ${ }^{30}$; however, it is logistically impractical for several reasons: (1) the Fontan must be taken down to accommodate a single-inflow, single-outflow device; (2) a systemic MCS device is not optimized to the very low pressure rise desired for cavopulmonary assist, increasing risk for device failure; (3) the right-sided circulation is dependent on the device, making device dysfunction lethal; and (4) device operational lifespan is limited and therefore not a longterm solution. Given these considerations, the use of existing MCS technology in Fontan circulations is limited to end-stage disease as a bridge therapy, if it is used at all.

\section{Technical Considerations for Long-Term Fontan Reversal}

Dedicated right-sided circulatory support of the Fontan circulation presents a number of caveats that are uniquely challenging (Table 2). Technically, a cavopulmonary assist device is not a ventricular assist device, because it provides support where no ventricle exists. It is intended to function as a low-input auxiliary right-sided pump to maintain low systemic venous pressure and preload to the systemic ventricle, identical to the essential function of the right ventricle in a biventricular circulation. ${ }^{31}$

Although a von Karman viscous pump is a relatively weak pump, its inherent performance is ideal for the Fontan circulation. As a dynamic pump, it can provide consistent pressure rise across a wide range of cardiac output, making it responsive to physiologic demand. Low hydraulic efficiency also makes it less likely to generate suction, vein collapse, and cavitation and makes it tolerant of physiologic variation in systemic venous return. Similarly, it is unlikely to generate excessive downstream pressure, reducing the risk of lung perfusion injury. Most existing MCS devices are displacement pumps that must vary rotational speed to vary flow rate, making them susceptible to suction and unresponsive to physiologic demand, thereby limiting exercise capacity.

The TCPC is the best-known geometry for passive cavopulmonary flow. ${ }^{22}$ Our strategy has therefore been to retain the TCPC as a default flow path and design an anatomically specific pump to add pressure energy within it. A central diverting body at the TCPC intersection will split incoming flow toward each outlet, significantly reducing turbulent energy loss. ${ }^{32,33}$ By rotating a central stabilizing body, suspended within the TCPC independent of the vessel walls, fluid pressure and velocity are increased, transforming it from a static flow diverter to a pump. We also anticipate that a permanently implanted device will eventually fail. In a Fontan circulation, a pump situated in the center of the flow path cannot impede flow (Figure 5). This is a critical safety consideration in young patients with Fontan circulations who have decades of life expectancy ahead of them.

The ideal pressure rise for a cavopulmonary assist device is not yet clinically determined. We have shown in this study, and in other in vitro mock circulatory studies of a Fontan circulation, that $6 \mathrm{~mm} \mathrm{Hg}$ pressure step-up will restore biventricular equivalency under normal physiologic conditions. ${ }^{7,34}$ This pressure rise correlates with normal circulatory physiology. The presence of increased pulmonary vascular resistance in the Fontan circulation may affect the magnitude of pressure rise required. Extremely elevated pulmonary resistance is incompatible with late Fontan survival; we therefore believe that the need for a pressure increase significantly greater than 


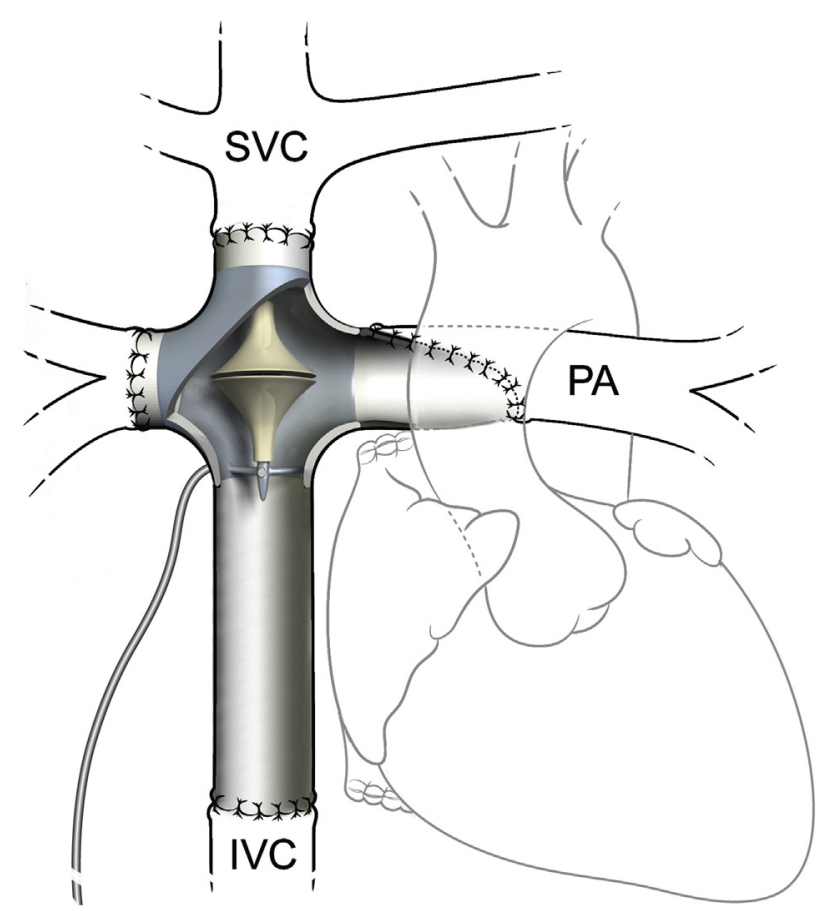

FIGURE 5. Pump implantation (conceptual). The cavopulmonary assist device is implanted in situ in the total cavopulmonary connection and serves to augment cavopulmonary flow modestly. The device is compatible with either lateral tunnel or extracardiac conduit Fontan construction. Graft extensions allow for suturing, with a total of 4 anastomoses. Grafts can be extended or tailored to address anatomic issues. To facilitate device exchange in the event of dysfunction, it is possible to replace the device through the modular "quick connects" that attach each limb to the pump body. Two pumps are depicted. The systemic ventricle performs most of the workload. It is served by a low-input cavopulmonary assist device to normalize preload to the systemic ventricle, in addition to reducing systemic venous pressure. $S V C$, Superior vena cava; $P A$, pulmonary artery; $I V C$, inferior vena cava.

approximately $15 \mathrm{~mm} \mathrm{Hg}$ is unlikely. Further, in the cavopulmonary circulation, the margin to apply an aggressive pressure step-up is limited by baseline systemic venous pressure. For example, the application of a $20 \mathrm{~mm}$ $\mathrm{Hg}$ pressure step-up in the TCPC in which baseline systemic venous pressure is $16 \mathrm{~mm} \mathrm{Hg}$ will induce negative $(-4 \mathrm{~mm} \mathrm{Hg})$ systemic venous pressure, leading to suction collapse and flow disruption.

In general, MCS devices are not placed in line or in series with the circulation, but rather are placed in parallel (ie, paracardiac) because of the risk of device obstruction of the native flow path. This concern is amplified for a Fontan pump situated in the lowest pressure segment of the circulation, where seemingly trivial obstruction can induce hemodynamic instability. An implantable Fontan pump must have no potential for mechanical obstruction in the event of dysfunction.

\section{Emerging Technologies}

Concepts for dedicated Fontan circulatory support are currently evolving. ${ }^{34,35}$ To date, nearly all have focused on modification of existing technology (unidirectional axial or centrifugal ventricular assist devices) to operate in the low-pressure Fontan environment. Although these devices may suffice as bridge therapy, they lack the technologic rigor required for safe and durable long-term support. They are incapable of supporting flow in all 4 limbs of the cavopulmonary connection and will induce back-pressure elevation in the opposing systemic venous territory. They are capable of mechanical obstruction, a prohibitive issue when the right-sided circulation is dependent on the device. Because of motor configuration, they may be bulky and not fit within the confines of the TCPC. Finally, if the Fontan pathway is modified to accommodate a unidirectional flow device, the resulting pathway will not support passive cavopulmonary flow in the event of device dysfunction. With respect to safety and durability, a Fontan pump that offers multidirectional flow, in situ anatomic placement, and a contingency plan for failure is preferable.

\section{Clinical Implications}

Cavopulmonary assist reframes single-ventricle palliation from a problem with no solution to a problem with an obvious solution. The challenge lies in creating a technology that can safely and durably implement it. If successfully translated, it would represent a first-ever targeted therapy for Fontan failure. It would also permit biventricular equivalency to be maintained in a univentricular circulation before clinical failure, preempting Fontan disease. The ideal timing for device intervention is not yet known. For patients with Fontan circulations, who have few options to alter their inevitable disease progression, this concept may fill a significant gap in the existing armamentarium of surgical therapies with a more comprehensive solution that has exciting potential to shift the paradigm for single-ventricle therapy from palliation to cure.

The clinical vision for a Fontan-specific cavopulmonary assist device is greatly different from current MCS strategy. Rather than reserving MCS for end-stage salvage, it may be better to apply it preemptively for biventricular health maintenance. The device thus may not necessarily be limited to advanced Fontan failure, and may be considered earlier. For patients with Fontan circulations, the implications are starkly different: a lifetime of chronic disease progression with systemic MCS as end-stage therapy versus cavopulmonary assist to enable long-term biventricular health and wellness, potentially for decades.

\section{Limitations}

This report presents early-stage electromechanical feasibility for an implantable cavopulmonary assist device 
concept. Such a therapy has never been implemented clinically; discussion of clinical application and duration of support is therefore theoretic. Substantial technologic development remains to be performed. Thrombogenicity and hemolysis performance remain to be determined, and device durability is unknown. The power source has not yet been determined, although the device is envisioned to be powered wirelessly. Until a device is fully developed and enters clinical trial, the translational effect of longterm Fontan reversal will remain speculative.

\section{CONCLUSIONS}

After Fontan repair of single functional ventricle, patients are trapped for the remainder of their lives in a cycle of chronic circulatory inefficiency. Despite dramatic improvements in surgical technique, perioperative care, and long-term surveillance, late Fontan failure and attrition remain an intractable problem for which there is no primary or preventive therapy. An early-stage implantable cavopulmonary assist device shows promising potential to reverse the Fontan paradox and preempt Fontanassociated disease as a curative therapy. It represents a significant opportunity to shift the paradigm for single-ventricle care fundamentally to one based on biventricular health.

\section{Webcast}

You can watch a Webcast of this AATS meeting presentation by going to: https://aats.blob.core.windows.net/media/19\% 20AM/Tuesday_May7/202BD/202BD/S97\%20-\%20Fontan $\% 20$ surgery $\% 20$ and $\% 20$ complications $\% 20-\% 20$ Surgical \%20Treatment/S97_6_webcast_083654885.mp4.

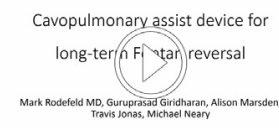

\section{Conflict of Interest Statement}

Dr Rodefeld discloses patent US 9,827,357 for cavopulmonary viscous impeller assist device and method. Dr Giridharan discloses interuniversity contract with IU for device (Dr Rodefeld) and consultant status for NuPulseCV, which is developing a counterpulsation device; the present work is unrelated (Fontan support). All other authors have nothing to disclose with regard to commercial support.

\footnotetext{
References

1. Fontan F, Baudet E. Surgical repair of tricuspid atresia. Thorax. 1971;26: 240-8.
}

2. Kreutzer G, Galindez E, Bono H, DePalma C, Laura JP. An operation for the correction of tricuspid atresia. J Thorac Cardiovasc Surg. 1973;66: 613-21.

3. de Leval MR. The Fontan circulation: what have we learned? What to expect? Pediatr Cardiol. 1998;19:316-20.

4. Rychik J. The relentless effects of the Fontan paradox. Semin Thorac Cardiovasc Surg Pediatr Card Surg Annu. 2016;19:37-43.

5. Gewillig M, Brown SC. The Fontan circulation after 45 years: update in physiology. Heart. 2016;102:1081-6.

6. Rodefeld MD, Boyd JH, Myers CD, Lalone BJ, Bezruczko A, Potter AW, et al. Cavopulmonary assist: circulatory support for the univentricular Fontan circulation. Ann Thorac Surg. 2003;76:1911-6.

7. Rodefeld MD, Coats B, Fisher T, Giridharan GA, Chen J, Brown JW, et al. Cavopulmonary assist for the univentricular Fontan circulation: von Karman viscous impeller pump. J Thorac Cardiovasc Surg. 2010; 140:529-36.

8. Fontan F, Kirklin JW, Fernandez G, Costa F, Naftel DC, Tritto F, et al. Outcome after a "perfect" Fontan operation. Circulation. 1990;81: 1520-36.

9. Kreutzer C, Kreutzer J, Kreutzer GO. Reflections on five decades of the Fontan Kreutzer procedure. Front Pediatr. 2013;1:45-60.

10. de Leval MR. The Fontan circulation: a challenge to William Harvey? Nat Clin Pract Cardiovasc Med. 2005;2:202-8.

11. Rychik J. Forty years after the Fontan: a failed strategy. Semin Thorac Cardiovasc Surg Pediatr Card Surg Annu. 2010;13:96-100.

12. Veldtman GR, Opotowsky AR, Wittekind SG, Rychik J, Penny DJ, Fogel M, et al. Cardiovascular adaptation to the Fontan circulation. Congenit Heart Dis. 2017; 12:699-710.

13. Diller GP, Kempny A, Alonso-Gonzalez R, Swan L, Uebing A, Li W, et al. Survival prospects and circumstances of death in contemporary adult congenital heart disease patients under follow-up at a large tertiary centre. Circulation. 2015; 132:2118-25.

14. Pundi KN, Johnson JN, Dearani JA, Li Z, Hinck CA, Dahl SH, et al. 40-year follow-up after the Fontan operation: long-term outcomes of 1,052 patients. $J$ Am Coll Cardiol. 2015;66:1700-10.

15. Poh CL, Zannino D, Weintraub RG, Winlaw DS, Grigg LE, Cordina R, et al. Three decades later: the fate of the population of patients who underwent the atriopulmonary Fontan procedure. Int J Cardiol. 2017;231:99-104.

16. Rodefeld MD. The Fontan circulation: time for a moon shot? J Thorac Cardiovasc Surg. 2018;156:252-3.

17. Anderson PA, Sleeper LA, Mahony L, Colan SD, Atz AM, Breitbart RE, et al. Contemporary outcomes after the Fontan procedure: a pediatric heart network multicenter study. J Am Coll Cardiol. 2008;52:85-98.

18. Averin K, Hirsch R, Seckeler MD, Whiteside W, Beekman RH, Goldstein BH. Diagnosis of occult diastolic dysfunction late after the Fontan procedure using a rapid volume expansion technique. Heart. 2016;102: 1109-14.

19. De Mey W, Cools B, Heying R, Budts W, Louw JJ, Boshoff DE, et al. Can a volume challenge pinpoint the limiting factor in a Fontan circulation? Acta Cardiol. 2015;70:536-42.

20. Rathod RH, Prakash A, Powell AJ, Geva T. Myocardial fibrosis identified by cardiac magnetic resonance late gadolinium enhancement is associated with adverse ventricular mechanics and ventricular tachycardia late after Fontan operation. $J$ Am Coll Cardiol. 2010;55:1721-8.

21. Ross HJ, Law Y, Book WM, Broberg CS, Burchill L, Cecchin F, et al; American Heart Association Adults With Congenital Heart Disease Committee of the Council on Clinical Cardiology and Council on Cardiovascular Disease in the Young, the Council on Cardiovascular Radiology and Intervention, and the Council on Functional Genomics and Translational Biology. Transplantation and mechanical circulatory support in congenital heart disease: a scientific statement from the American Heart Association. Circulation. 2016; 133:802-20.

22. Bove EL, de Leval MR, Migliavacca F, Balossino R, Dubini G. Toward optimal hemodynamics: computer modeling of the Fontan circuit. Pediatr Cardiol. 2007; 28:477-81.

23. Sundareswaran KS, Pekkan K, Dasi LP, Whitehead K, Sharma S, Kanter KR, et al. The total cavopulmonary connection resistance: a significant impact on single ventricle hemodynamics at rest and exercise. Am J Physiol Heart Circ Physiol. 2008;295:H2427-35.

24. Tang E, Restrepo M, Haggerty CM, Mirabella L, Bethel J, Whitehead KK, et al. Geometric characterization of patient-specific total cavopulmonary connections 
and its relationship to hemodynamics. JACC Cardiovasc Imaging. 2014;7: 215-24.

25. Marsden AL, Bernstein AJ, Reddy VM, Shadden SC, Spilker RL, Chan FP, et al. Evaluation of a novel Y-shaped extracardiac Fontan baffle using computational fluid dynamics. J Thorac Cardiovasc Surg. 2009;137:394-403.

26. Arnaoutakis GJ, Blitzer D, Fuller S, Eckhauser AW, Montenegro LM, Rossano JW, et al. Mechanical circulatory support as bridge to transplantation for the failing single ventricle. Ann Thorac Surg. 2017;103:193-7.

27. Horne D, Conway J, Rebeyka IM, Buchholz H. Mechanical circulatory support in univentricular hearts: current management. Semin Thorac Cardiovasc Surg Pediatr Card Surg Annu. 2015;18:17-24.

28. Adachi I, Burki S, Fraser CD Jr. Current status of pediatric ventricular assist device support. Semin Thorac Cardiovasc Surg Pediatr Card Surg Annu. 2017;20: $2-8$.

29. Woods RK, Ghanayem NS, Mitchell ME, Kindel S, Niebler RA. Mechanical circulatory support of the Fontan patient. Semin Thorac Cardiovasc Surg Pediatr Card Surg Annu. 2017;20:20-7.

30. Prêtre R, Häussler A, Bettex D, Genoni M. Right-sided univentricular cardiac assistance in a failing Fontan circulation. Ann Thorac Surg. 2008;86:1018-20.

31. Furey SA, Zieske HA, Levy MN. The essential function of the right ventricle. Am Heart J. 1984;107:404-10.

32. Soerensen DD, Pekkan K, de Zelicourt D, Sharma S, Kanter K, Fogel M, et al. Introduction of a new optimized total cavopulmonary connection. Ann Thorac Surg. 2007;83:2182-90.

33. Desai K, Haggerty CM, Kanter KR, Rossignac J, Spray TL, Fogel MA, et al. Haemodynamic comparison of a novel flow-divider Optiflo geometry and a traditional cavopulmonary connection. Interact Cardiovasc Thorac Surg. 2013; $17: 1-7$.

34. Rodefeld MD, Frankel SH, Giridharan GA. Cavopulmonary assist: (Em)powering the univentricular Fontan circulation. Semin Thorac Cardiovasc Surg Pediatr Card Surg Annu. 2011;14:45-54.

35. Broda CR, Taylor DA, Adachi I. Progress in experimental and clinical subpulmonary assistance for Fontan circulation. J Thorac Cardiovasc Surg. 2018;156:1949-56.

Key Words: Fontan, single ventricle, mechanical circulatory support

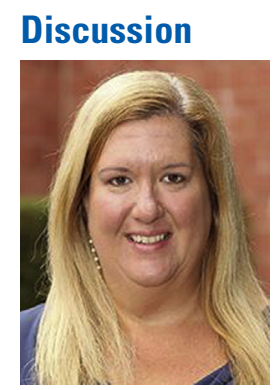

Dr Cynthia S. Herrington (Los Angeles, Calif). I just so happen to be your discussant, and I am not going to reiterate all the issues and problems of the Fontan circulation, because I feel that many other people want to come up to the mike and maybe ask questions, because that's the stage that you are in right now with the device, but I do have a number of questions.

First, do you have one of the flow videos for when the pump stops, what that looks like when the pump stops?

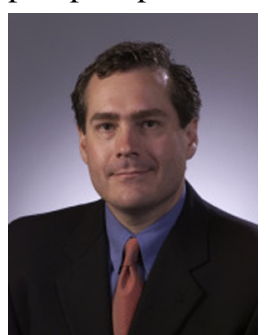

Dr Mark D. Rodefeld (Indianapolis, Ind). No, I don't. In the videos I showed, all the flow is induced by the pump. Although I can provide video showing passage of flow at $0 \mathrm{rpm}$, I don't have it for this presentation. Dr Herrington. It is not that I don't believe you, but I just would like to see what that looks like, being a visual person.
Dr Rodefeld. Agreed.

Dr Herrington. I know that you are aiming for an increase in downstream pressure about 4 to $6 \mathrm{~mm} \mathrm{Hg}$. What kind of a drop might we see in the central venous pressures with the device when it is running at the levels that you have it running at?

Dr Rodefeld. The pressure drop upstream should match the pressure increase downstream in the pulmonary arteries. So, if the pump is rated to provide a $\Delta \mathrm{P}$ of 4 or $6 \mathrm{~mm} \mathrm{Hg}$, it should drop systemic venous pressure by 4 or $6 \mathrm{~mm} \mathrm{Hg}$ and increase pulmonary artery pressure by 4 or $6 \mathrm{~mm} \mathrm{Hg}$. There will be additional pressure loss across the transpulmonary gradient, and therefore preload may increase by 1 to $3 \mathrm{~mm} \mathrm{Hg}$.

There is controversy about pulmonary resistance in Fontan circulations and whether higher pressure rise is needed from the device. Our target thus far has been to emulate normal circulatory physiology. It may be necessary to add a higher pressure rise with this device, and we are still at such an early stage that we don't know the answer to that.

Dr Herrington. I appreciated when I read your paperand by the way, I commend you on your tenacity for hanging in, and I have been rooting for you for a very long time, so I am very excited that we are at least at this stage that we can discuss it. As I look at the way you presented it, it almost seems as though it is something that we would implant when we do the Fontan, or at the very early signs that we have an issue that in the later phases. Although it may work if you have retained systolic function, if you are having a true failing Fontan, I worry about that because I think the hearts turn into leather at that point; I think the lungs get in the center. But what you are basically saying is that this pump would not be able to push into a high-resistance lung?

Dr Rodefeld. It could be modified to do that, but I would echo your comment that it is probably better as a preemptive device and not an end-stage device. So, yes, this pump can be modified to generate higher pressure. That comes at the cost of obstruction risk; the higher the pressure rise, the more obstruction risk you have with the device. Depending on the situation of a particular patient, however, obstruction risk may not be as much of a concern.

Dr Herrington. I am going to ask one more question, so if anybody else has questions, you can jump up, because I think we do have a little bit of time.

With respect to imaging, maybe this is a downstream question, but I am going to want to know when the device is spinning and when it isn't spinning. So, what would imaging look like for this? Do you think it would be obvious by our standard imaging, by echocardiography and whatnot?

Dr Rodefeld. I think it will be. You will see flow effect from the spinning device, but in terms of seeing the device itself, I don't think that echocardiography will be able to 
image that. The device probably will have feedback sensors that will tell you if it is spinning or not.

Unidentified Speaker. [No audio]

Dr Rodefeld. In mock loops, you can put Penrose drains upstream and mimic a flaccid vena cava, for example. The inferior and superior venae cavae have a lot of structure around them. They are not necessarily dangling in the breeze, and not necessarily completely flaccid. All our work thus far has focused on hydraulics, motor performance, and electromechanical issues. We will do future analyses in a mock loop with distensible or compressible veins.

I can tell you that we have clamped inflow by $50 \%$, and we saw a drop in pressure immediately before the pump, but it wasn't in the negative range. With complete occlusion, it will go negative, but physiologically complete occlusion of inflow should be transient. We have seen negative pressures as much as $-13 \mathrm{~mm} \mathrm{Hg}$ in a model. The good news is that at $-13 \mathrm{~mm} \mathrm{Hg}$, the pump didn't cavitate; in other words, it didn't pull air out of solution. It was still spinning at the same speed, but it did not cavitate.

Unidentified Speaker. [No audio]

Dr Rodefeld. The current version you saw is at about $7 \mathrm{~W}$ power requirement. The HeartWare device runs at about $4 \mathrm{~W}$, and with optimization, we are hoping that we will get it below $4 \mathrm{~W}$. It should require less power input than a systemic ventricular assist device, so we hope that it will be less than that.

As far as power source goes, we hope that it can be a wireless system. Ayoung, otherwise healthy patient with a Fontan circulation is not going to want to be plugged in and is not going to want to have to deal with driveline fractures and infections.

Unidentified Speaker. How close are you to trying this in an animal model?
Dr Rodefeld. It depends on funding. Potentially, it could be within 3 or 4 years.

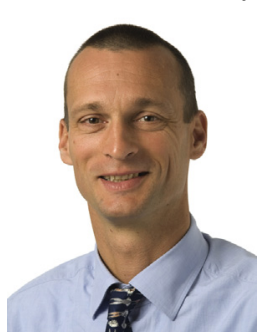

Dr Yves d'Udekem d'Acoz (Melbourne, Victoria, Australia). With the very small clearance between the internal part and the spinning part and the very small orifice going in and coming out, one would expect a lot of turbulence and platelet fibrin deposition and clotting of this internal part of the pump. Would it not be worthwhile to put this pump in a vena cava in an animal model with anticoagulation and find out whether it clots off after a certain amount of time?

Dr Rodefeld. Absolutely, and we are not there yet with biocompatibility. And I didn't present shear rate data. We do have preliminary shear rate data, and they are in an acceptable range. But, yes, hemocompatibility and thrombogenicity testing is going to be the next step.

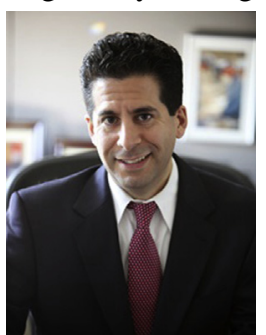

Dr David L. Morales (Cincinnati, Ohio). I just want to make one more comment. We keep talking about systolic dysfunction with Fontan failure, but we saw for those deaths it was only $25 \%$ to $30 \%$, but it's diastolic dysfunction that is vastly underestimated, which is why I agree with Mark about this being a preemptive device. Once the Fontan circulation has really started to fail, forcing blood through an abnormal vasculature into a restrictive ventricle is probably not a long-term solution, and that's why this device preemptively could maybe affect this and not have a restrictive physiology that the ventricle has. It is not the systolic function mostly, it is the restrictive, I think.

Dr Rodefeld. Yes, I agree. 